\title{
Measuring Equity in Intimate Relations
}

\author{
Jane Traupmann \\ Wellesley College
}

Robert Petersen

Abt Computer Graphics Corporation

Mary Utne

University of Chicago

\author{
Elaine Hatfield \\ University of Hawaii at Manoa
}

cepted systems for equity and will attempt to induce members to accept and adhere to these systems.

Proposition IIB: Groups will generally reward members who treat others equitably and will generally punish members who treat others inequitably.

Proposition III: When individuals find themselves participating in inequitable relationships, they will become distressed. The more inequitable the relationship, the more distress they will feel.

Proposition IV: Individuals who discover they are in inequitable relationships will attempt to eliminate their distress by restoring equity. The greater the inequity that exists, the more distress they will feel, and the harder they will try to restore equity.

Equity theorists define an equitable relationship to exist when the person scrutinizing the relationship (whether Participant A or Participant $\mathrm{B}$, or an outside observer) concludes that all participants are receiving equal relative gains from the relationship, that is, when

$$
\frac{\left(0_{A}-I_{A}\right)}{\left(\left|I_{A}\right|\right)^{k_{A}}}=\frac{\left(0_{B}-I_{B}\right)}{\left(\left|I_{B}\right|\right)^{k_{B}}},
$$

where

$$
I_{A} \text { and } I_{B} \text { designate "the scrutineer's" }
$$


perception the inputs of Person A and Person B,

$O_{A}$ and $O_{B}$ designate the scrutineer's perception of the outcomes of Person $A$ and Person B, and

$\left|I_{A}\right|$ and $\left|I_{B}\right|$ designate the absolute value of the inputs (i.e., the perceived value of their inputs, disregarding sign) of Person A and Person B.

Adams (1963) and Walster, Walster, and Berscheid (1978) contend that since inequity is distressing-the overbenefited person feels guilty at reaping undeserved benefits and the underbenefited feels angry at being taken advantage of-a change toward greater equity will be stimulated.

Equity theory has been usefully applied to such diverse relationships as business relationships (e.g., Pritchard, Dunnette, \& Jorgenson, 1972), bystander/victim relationships (e.g., Piliavin \& Piliavin, 1972), and altruistic relationships (e.g., Dillon, 1968; Gross, Piliavin, Walston, \& Broll, 1973). For example, Gross et al. (1973) cited evidence from Briar's (1966) extensive interviews with welfare recipients as indicating that the welfare recipients felt they must give up freedom as "payment" for financial aid. Welfare families felt obligated to follow social workers' suggestions on budgets, psychiatric visits, and marriage counseling; and many felt that they did not have the right to refuse entry to their homes at night by the social worker. (See Walster et al., 1978, for an extensive summary and discussion of applications of equity theory.)

Despite the extensive literature generated by equity theorists, little attention has been paid to the development of a measure of inequity. Inequity is inevitably manipulated in experimental or quasi-experimental paradigms rather than measured in natural settings. Adams and Freedman (1976), in a critical look at the progress equity theorists had made, concluded that there was a great need for the "development of psychometric technology for the measurement of the components of inequity."
What would be the basic properties of a measure of equity? Walster et al. (1978) have contended that in order to calculate the "equitableness" of a relationship, participants must first evaluate their own and their partners' inputs and outcomes and then must calculate equity/ inequity. These authors defined inputs as the "participant's contributions to the exchange, which are seen by a scrutineer as entitling him [or her] to reward or cost." Outcomes are defined as "the positive and negative consequences that a scrutineer perceives a participant has received in the course of his [or her] relationship with another. The participant's outcomes, then, are equal to the rewards he [or she] obtains from the relationship minus the costs he [or she] incurs" (p. 11-12).

Theorists who are interested in measuring the equity calculation process must find ways of getting individuals to make their private, fleeting, semiconscious thoughts public. A measure of equity would consist of a list of inputs and outcomes that are relavant to a particular relationship type and a scale to assess the values of these inputs and outcomes. In order to develop a measure of equity, four tasks must be completed:

1. The domain of items that are relevant to the particular relationship type must be specified;

2. The set of items which adequately represents that domain must be selected;

3. The reliability of the measure must be assessed; and

4. The validity of the measure must be assessed.

This paper describes the work done on each of these four tasks in the development of the Traupmann-Utne-Walster (TUW) Scales, which measure participants' perceptions of fairness or equity in an intimate relationship. Initially, two intimacy types-couples who were dating steadily and couples who had recently been married-were used as target populations.

It should be noted that the TUW Scales are general enough to be used with only slight modifications for studying the relationships of couples who are living together, as well as of 
couples who are not. Furthermore, the procedures could be used to develop an equity index for any close dyadic relationship. Researchers interested in assessing the equitableness of, for example, parent-child relations, teacher-pupil relations, or relations among same-sex friends will find this method useful as a guide in developing their own equity scales.

\section{Mapping the Content Domain}

The task of identifying the inputs and outcomes that intimates consider to be important included several informal interviews with volunteer couples who either were dating steadily or were married about their relationships (see Traupmann, 1978). Among the most important benefits couples said they obtained from their dating or marital relationships were "understanding," "companionship," "love," "stability," and, somewhat surprisingly, "a good sense of humor."

Secondly, a survey of the sociological (e.g., Burgess \& Cottrell, 1939; Burgess \& Wallin, 1953), social psychological (Levinger, 1974; Murstein, 1970), and clinical (Hopps, Willis, Weiss, \& Patterson, 1972; Stuart, 1972) litera. ture on dating and mate selection was conducted in order to identify other inputs and outcomes that might be important to intimates.

The insights gained from the informal interviews and the literature search were refined into lists of inputs and outcomes in close relationships. The lists included some fundamental traits or characteristics that remain important during all stages of relationship development (Murstein, 1970), such as understanding and concern, affection, intelligence, and appreciation. In addition, the lists included some inputs and outcomes that would be especially relevant to dating couples (e.g., "good-looking," "fun to be with," "popularity") and others designed for married couples (e.g., "sharing interests," "sexual compatibility," "decision-making responsibility"). This follows from the stage theorists' (e.g., Levinger, 1974) suggestion that very differ- ent concerns may take on importance for one or both members of the couple at different developmental stages. ${ }^{1}$ The lists were combined to produce a set of 34 input items (12 Fundamental, 10 Dater, and 12 Married) and a comparable set of 34 outcome items.

\section{Pretest 1: Selecting the Items}

Pretest 1 was designed with two theoretical goals in mind. The first was to determine whether those couples who were dating steadily (Daters) and those who were recently married (Marrieds) perceived the Dater and Married items to be as differentially important to their relationships as the stage theorists would suggest. It was expected that although both groups would rate the Fundamental items as quite important, the Daters and Marrieds would differ substantially in their ratings of the Dater and Married items.

The second goal was to identify items that clearly fell outside of the domain of important concerns in intimate exchanges. Inputs and outcomes that received "low importance" ratings from both groups would then be eliminated from the lists. More stringent procedures for domain mapping and item selection to insure a representative collection of items (Nunnally, 1967), though desirable, were not possible due to funding limitations.

\section{Method}

Respondents. Potential respondents, people who were either dating steadily or who had recently been married, were contacted in lecture classes at the University of Wisconsin, in businesses employing large numbers of young people (banks, credit unions), and in a University-operated married student housing project.

Sixty-seven Daters and 68 Marrieds returned completed questionnaires. Four Daters and four

\footnotetext{
'For the purposes of this study it was assumed that these young couples did not yet have children and therefore items relevant to children were not included in the scales.
} 
Marrieds were discarded because their reported length of relationship exceeded the maximum criterion of 1 year. The final subject pool consisted of 60 Daters ( 29 males and 31 females, 6 of whom were couples) and 63 Marrieds (36 males and 27 females, 10 of whom were couples).

Procedure. The respondents were asked to complete privately a self-administered questionnaire, which explored their current dating or marriage relationship. The questionnaire included the lists of 34 inputs and 34 outcomes. The respondents were asked to indicate on a Likert scale how important each of the items was to their relationship. Possible answers ranged from "not at all important=1" to "extremely important $=6 . "$ Respondents were asked to write in at the end of the list concerns in their relationship that were not included in the lists. ${ }^{2}$

\section{Results}

Factor analysis. If the Fundamental items truly reflect concerns common to couples at all stages of a relationship, and if the Dater and Married items truly reflect concerns unique to the two groups, factor analyses of Daters' and Marrieds' responses separately and of the total data pool should reveal this pattern of differences.

The Dater, Married, and Fundamental items were jointly entered into a principal components factor analysis of the correlation matrix using a varimax rotation. Responses from the Daters and Marrieds were analyzed separately and as one pooled group. The final analysis revealed six meaningful factors in the input data and six in the outcome data (minimum loading value was .30 ), reflecting only the content of the items.

${ }^{2}$ The experience of completing the questionnaire sparked a good deal of conversation between experimenters Traupmann and Utne and the respondents, which proved to be extremely informative. The respondents indicated that they understood the questions and that they felt the topics were quite meaningful to them. They also criticized the wording of items and suggested items that had been left out, thus contributing greatly to the improvement of the scales.
Thus, the results did not lend support to the prediction.

Analysis of variance. If Daters and Marrieds responded to the Fundamental, Dater, and Married items as predicted, there should be no significant differences between groups on the Fundamental items but strong differences in the appropriate direction for the Dater and the Married items.

Using subject category (Dater vs. Married) as the independent variable, a one-way analysis of variance was run for each item. The results of the analyses of variance made it clear that dating and married persons were not differentially concerned with most of the items. The few differences that were found did not fit into a sensible pattern. (For these results, see Traupmann, 1978.) Thus, the results of both factor analyses and the analyses of variance did not support the three-factor prediction.

On the basis of these results, it was concluded that married people still notice personal characteristics such as good looks and social grace, and that daters are concerned about fairly intimate "emotional" qualities, such as acceptance and sexual fidelity. Therefore, the idea of different lists of items for different relationship stages was abandoned; and instead, one list of inputs and another of outcomes were produced. Retained were those items that received relatively high importance ratings by both groups. Discarded were items judged to be low in importance. Many of the items were reworded, streamlined, or clarified. The items were organized into four content areas, or subscales, that seemed to cluster together on the basis of the pretest results: (1) Personal Concerns, (2) Emotional Concerns, (3) Day-to-Day Concerns, and (4) Opportunities Gained or Lost. ${ }^{3}$

\footnotetext{
${ }^{3}$ It is the total scale that is of primary interest to equity theorists. However, the subscales may prove useful to researchers and practitioners with interests in particular aspects of intimate relating. For example, theorists exploring the differences between men's and women's emotional expressiveness may find the Emotional Concerns subscale useful, and marital therapists might help couples to understand their marriage better through an analysis of its several components.
} 


\section{Total Inputs Scale}

Personal Concerns. The first 4 items of the Total Inputs Scale are qualities that people notice upon first encounters-good looks, social graces, and intelligence.

Emotional Concerns. The next 10 items are inputs that come into play as the relationship progresses toward greater intimacy. These items include feelings of love and liking, understanding, acceptance, sexual pleasure, sexual fidelity, commitment, and respect for one's partner's need for personal freedom.

Day-to-Day Concerns. The last 8 input items reflect the daily sorts of concerns couples encounter when they live together. Such things as day-to-day maintenance, finances, companionability, conversation, decision-making, and remembering special occasions are included here.

\section{Total Outcomes Scale}

The Total Outcomes Scale, structured similarly to the Total Inputs Scale, includes a set of 4 Personal Rewards, a set of 10 Emotional Rewards, and a set of 8 Day-to-Day Rewards. Two additional outcome items, measuring Opportunities Gained or Lost, complete the Total Outcomes Scale. The first of these, "chance to be married," identifies the benefits the society bestows upon its married members but generally withholds from singles, i.e., a chance to be a parent and even a grandparent, a chance to partake of "married couple events," and someone to grow old with. The second, "opportunities foregone," describes some of the things one gives up to be married.

\section{Pretest 2: Reliability Assessment}

The main purpose of Pretest 2 was to gather reliability information. An internal consistency measure was used as the index of reliability, since the Total Input and Outcome Scales were constructed as a global measure of the exchanges occurring in marriage. Though the content of the items varies, the underlying concept of marital exchange describes all items; thus, the total scales should be reasonably internally consistent.

\section{Method}

Respondents. The respondents were recruited through an advertisement in the local newspaper and through posters on campus. Couples married 2 years or less were offered the opportunity to participate in an interview study of marriage being conducted at the University of Wisconsin. Respondents were told that the confidential one-to-one interviews lasted approximately an hour and that they would be paid $\$ 2$ for their time and cooperation. In all, 36 eligible persons (16 married couples and four married women) responded and were interviewed.

Procedure. Husbands and wives were interviewed separately by one of eight trained interviewers. The interviewers first explained the concepts of "input" and "outcome" and how these concepts were being used to study marital relations. Interviewers presented the list of inputs. They asked respondents to read each input item and then indicate how positive or negative they felt their contribution was in that area. Possible scores ranged from 8 (extremely positive) to 1 (extremely negative). Then, interviewers presented the outcomes list. They asked respondents to evaluate how positive or negative each outcome was for them using the same scale. The responses to the items were combined by scale, and Cronbach's alpha (Nunnally, 1967) was calculated for the Total Inputs Scale and the Total Outcomes Scale.

\section{Results}

If the Total Inputs and Outcomes Scales are internally consistent, Cronbach's alpha should be fairly high. Though the content of the items is diverse, they do, nevertheless, assess various aspects of a whole-intimate relating. Thus, a reasonably high level of internal consistency was expected despite the diversity of content. Alpha co- 
efficients for the total scales were .90 for the Total Inputs Scale and .87 for the Total Outputs Scale.

\section{Validity Assessment}

\section{Method}

Respondents. The respondents were 118 couples who had obtained marriage licenses in Dane County, Wisconsin, during the months of August, September, October, and November of 1976. Thus, at the time of the interview, most respondents had been married between 3 and 8 months.

Procedure. Most of the 236 interviews were conducted in small research rooms in the University of Wisconsin Sociology Department. A few were conducted in the respondent's homes. Husbands and wives were interviewed separately and were assured of complete confidentiality, including confidentiality from their spouses.

The interview consisted of three parts. In Part I respondents were asked a series of demographic questions. In Part II they were asked to complete the TUW Scales using the procedures for administration described in Pretest 2 above. In Part III of the interview, respondents were asked to complete the Austin (1974) Measure of Contentment/Distress (reported in Walster et al., 1978) and a series of scales designed to measure the level of happiness, satisfaction, and stability in the marriage; these latter items were used to investigate the construct validity of the TUW Scales. (See Traupmann, 1978, and Utne, 1978, for further information about the interview.)

\section{Calculating Equity/Inequity}

Respondents' ratings of their own inputs in 22 areas, their own outcomes in 24 areas, and their perceptions of their partners' inputs again in 22 areas and outcomes in 24 areas were summed to produce four scores for each respondent: sum of own inputs, sum of own outcomes, sum of partner's inputs, and sum of partner's outcomes.
These four sums comprised the four components necessary to calculate the equitableness of the relationship, using the equations in Figure 1 to yield an index of the equitableness in the relationship from each respondent's point of view (see Walster, 1975, for a discussion of these formulas.)

The $E$ scores, ${ }_{w} E_{w}$ and ${ }_{H} E_{H}$, are indices of the degree of discrepancy between what the person feels he/she is actually getting from the relationship and what he/she feels he or she should get under equitable conditions. $E$ also indicates the direction of the discrepancy. That is, a large negative value indicates that the person is getting less than he or she feels is deserved-that he/she is underbenefited. A large positive $E$ value indicates the person is getting more than he or she feels is deserved-that he/she is overbenefited. An $E$ value that is either zero or near zero in either direction is considered to be equity-that the person is getting almost exactly what he or she feels is deserved.

Not surprisingly in this sample of newlyweds, the $E$ scores fell within a fairly narrow range. Little distress had surfaced in their "young" relationships. The small variance of the $E$ scores makes these data particularly difficult to relate to any other variable. Thus, any differences found between the groups would provide fairly strong evidence of the validity of the scales.

Respondents who received $E$ scores of less than -1.00 comprised the Underbenefited group $(n=44)$. Those who received scores greater than +1.00 were considered to be Overbenefited $(n=105)$. Those with scores between -.99 and +.99 were considered to be Equitably Treated $(n=87)$. The treatment of equity scores as categorical rather than continuous has been the tradition among equity theorists (e.g., Austin \& Waister, 1975; Leventhal, 1976).

\section{Results}

In order to provide data relevant to the construct validity of the TUW Scales, a strong association with other constructs predicted by equity 


\section{Figure 1}

Equity Formulae for Wives and Husbands

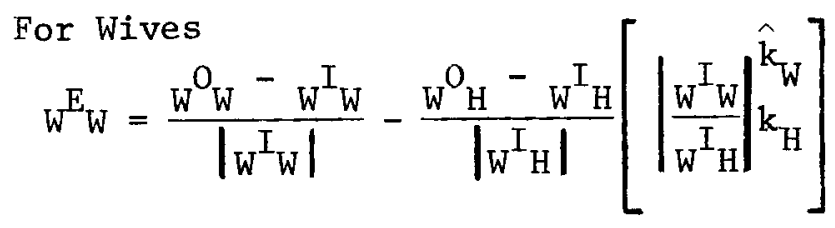

where $\quad \hat{k}_{W}=\operatorname{sign}\left({ }_{W} O_{H}-W_{H} I_{H}\right) \operatorname{sign}\left({ }_{W}{ }_{W}\right)$

$$
k_{H}=\operatorname{sign}\left({ }_{W} O_{H}-W_{H}{ }\right) \operatorname{sign}\left({ }_{W}{ }_{H}\right)
$$

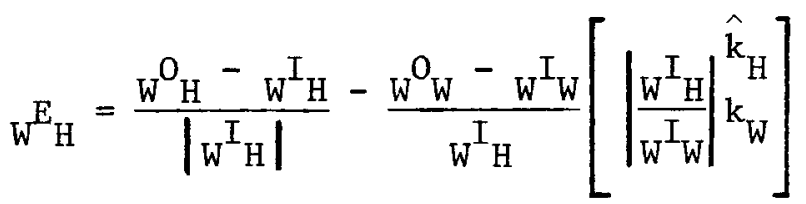

where $\hat{k}_{H}=\operatorname{sign}\left({ }_{W} O_{W}-{ }_{W} I_{W}\right) \operatorname{sign}\left({ }_{W}{ }_{H}\right)$

$$
\begin{aligned}
& k_{W}=\operatorname{sign}\left({ }_{W} O_{W}-W_{W} I\right) \operatorname{sign}\left({ }_{W} I_{W}\right) \\
& E Q=\left|E_{W}\right|+\left|{ }_{W} E_{H}\right|
\end{aligned}
$$

For Husbands

$$
\begin{aligned}
& H^{E_{H}}=\frac{H^{O}{ }_{H}-{ }_{H} I_{H}}{\left|H^{I}\right|}-\frac{H_{W}{ }^{O_{W}}-{ }_{H}{ }^{I}}{\left|H^{I}\right|}\left[\left|\frac{H^{I}{ }_{H}}{\mathrm{H}^{I}}\right|^{\hat{k}_{H}}{ }_{k_{W}}\right] \\
& \text { where } \hat{k}_{H}=\operatorname{sign}\left({ }_{H} O_{W}-{ }_{H} I_{W}\right) \operatorname{sign}\left({ }_{H} I_{H}\right) \\
& k_{W}=\operatorname{sign}\left({ }_{H} 0_{W}-{ }_{H} I_{W}\right) \operatorname{sign}\left({ }_{H} I_{W}\right)
\end{aligned}
$$

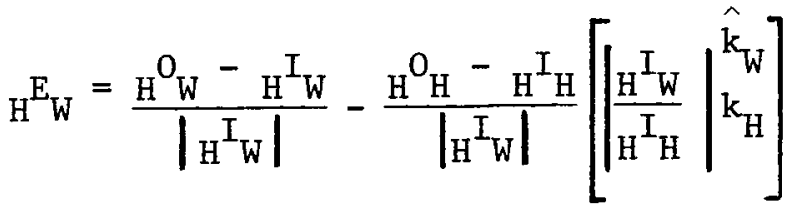

$$
\begin{aligned}
& \text { where } \hat{k}_{W}=\operatorname{sign}\left({ }_{H} O_{H}-{ }_{H} I_{H}\right) \operatorname{sign}\left({ }_{H} I_{W}\right) \\
& k_{H}=\operatorname{sign}\left({ }_{H} O_{H}-{ }_{H} I_{H}\right) \operatorname{sign}\left({ }_{H} I_{H}\right) \\
& \mathrm{EQ}=\left|\mathrm{H}^{\mathrm{E}} \mathrm{H}\right|+\left|\mathrm{H}^{\mathrm{E}} \mathrm{W}\right|
\end{aligned}
$$


theory must be shown. These constructs are (1) Affect, or contentment versus anger; and (2) Satisfaction/happiness with the relationship.

Affect. From Proposition III of equity theory, it was predicted that participants in inequitable marriages would feel less happy, less content, more angry, and more guilty than those in equitable marriages. Further, the overbenefited, though distressed by inequity, should be (understandably) less distressed than the underbenefited.

In order to embody these expectations in the statistical analyses, it was predicted a priori that the independent variable should be "scaled" as follows: overbenefited group $(+1)$, equitably treated group $(+2)$, underbenefited group $(+4)$. Thus, in the analyses, unequal interval linear and quadratic contrasts were used. The unequal spacing for the overbenefited $(\mathrm{O})$, equitably treated $(E)$, and underbenefited (U) groups in Figures 2 and 3 reflect this prediction.

The level of distress in the relationship was measured with four questions, which constitute the Austin (1974) Mood Scale.

When you think about your relationship-what you put into it ... and what you get out of it-and what your partner puts into it ... and what she/he gets out of it-how does that make you feel?

How content do you feel?

How happy do you feel?

How angry do you feel?

How guilty do you feel?

The 4-point response scale ranged from 1 (not at all) to 4 (very much).

As Figure 2 illustrates, the predictions were confirmed, with qualifications. Underbenefited women were less content than were equitably treated or overbenefited women $\left(F_{4,227}\right.$ [quadratic] $=3.89, p<.05$ ). This is what was expected. The men's data, though in the same direction, were not significant $\left(F_{4,227}\right.$ [quadratic] $=2.04$, $p<.09$ ). Overbenefited, equitably treated, and underbenefited women did differ in happiness scores as predicted, but these differences were not significant $\left(F_{4.227}\right.$ [quadratic] $=3.03$, $p<.08)$. Equitably treated men were significantly more happy than their inequitably treated counterparts $\left(F_{4.227}\right.$ [quadratic] $\left.=5.79, p<.02\right)$. All $F$ ratios are reported in Table 1 .

The negative affect results for women were surprising. Both underbenefited and overbenefited women were more angry than the equitably treated women $\left(F_{4.227}\right.$ [quadratic] $=7.08$, $p<.01)$. Overbenefited women were slightly, but not significantly, more guilty than the equitably treated and underbenefited women. The men were remarkably unmoved by guilt or anger. There were no significant differences between the three groups for either anger or guilt. The curve for guilt is virtually a straight line (see Table 1).

Austin's (1974) Total Mood Index, an overall index of affect, was calculated by summing the respondents' "content" and "happy" scores and subtracting their "anger" and "guilt" scores: Affect $=$ content + happy - angry - guilty. The higher the total score, the more content (and the less distressed) they are.

These results are also found in Figure 2 and Table 1 . The curve for women is precisely what was predicted: Equitably treated women were significantly more content (and less distressed) than the underbenefited and overbenefited women $\left(F_{4,227}\right.$ [quadratic] $\left.=9.38, p<.002\right)$. The results for men fell into the same pattern as that for women but were not significant $\left(F_{4,227}\right.$ [quadratic] $=2.07, p<.15$ ). Thus, it appears that over all, the TUW Scales are related to contentment/distress in the predicted way.

Satisfaction. A second construct which equity theory predicts is related to equity/inequity is the level of satisfaction/happiness with the relationship. The distress that inequities cause in marriage is likely to put a strain on the relationship. An imbalance in either a positive (overbenefited) direction or a negative (underbenefited) direction is likely to result in a rather negative feeling about the relationship, that is, less marital happiness and satisfaction. It was expected that the underbenefited would react more strongly than the overbenefited to inequity. 
Figure 2

The Affect Variables of Content, Happy, Angry, and Guilty and the Austin Total Mood Measure as a Function of the Perceived Equity/Inequity in the Marriage
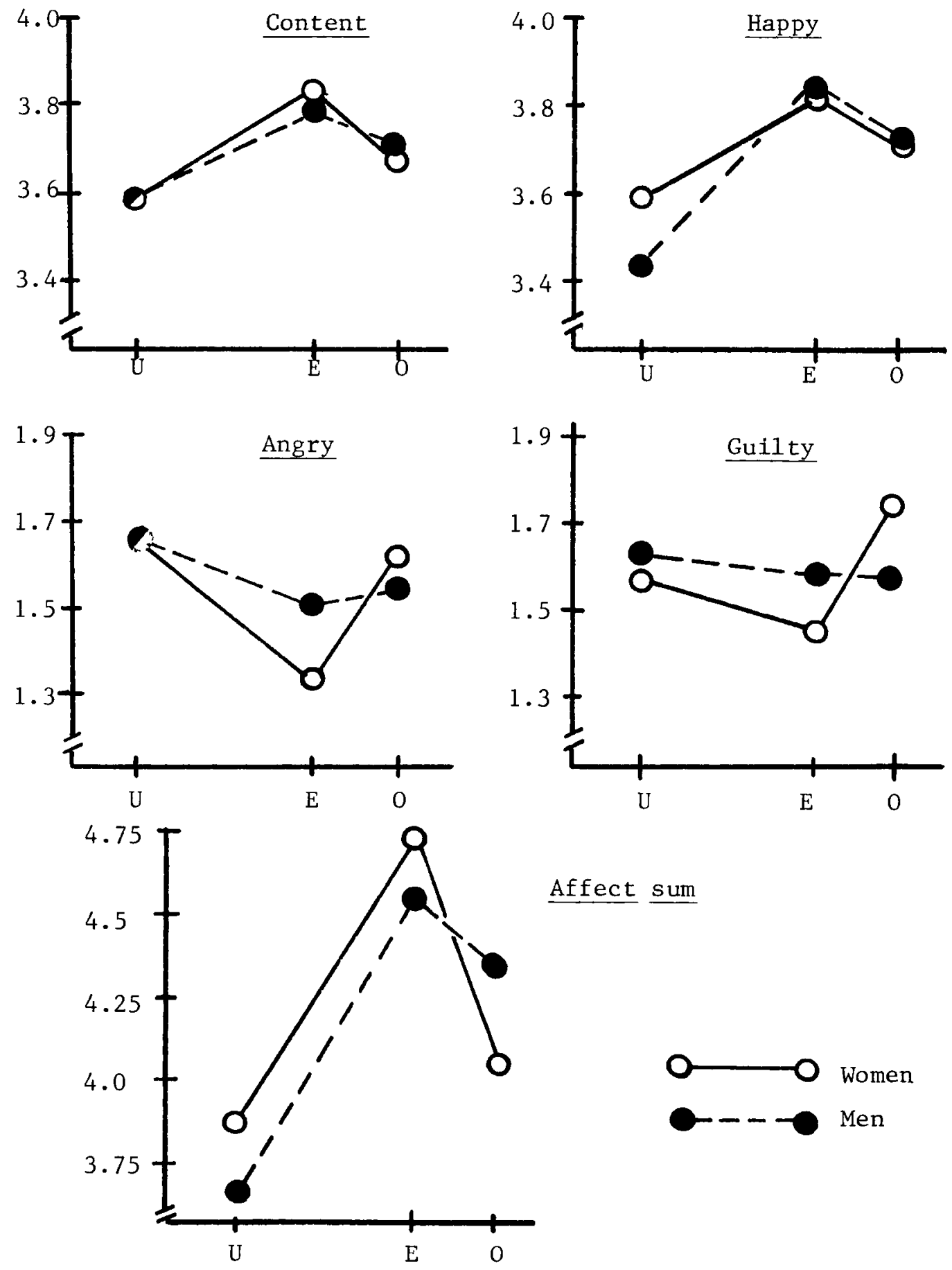

Downloaded from the Digital Conservancy at the University of Minnesota, http://purl.umn.edu/93227. May be reproduced with no cost by students and faculty for academic use. Non-academic reproduction requires payment of royalties through the Copyright Clearance Center, http://www.copyright.com/ 
Table 1

Means, Standard Deviations and Linear and Curvilinear F Ratios for Wives' and Husbands' Responses to the Austin (1974) Measure of Contentment/Distress

\begin{tabular}{|c|c|c|c|c|c|c|}
\hline \multirow[b]{2}{*}{ Scale } & \multirow{2}{*}{$\begin{array}{l}\text { Under- } \\
\text { benefit } \\
\text { Mean }\end{array}$} & \multirow[b]{2}{*}{$\begin{array}{l}\text { Equity } \\
\text { Mean }\end{array}$} & \multirow{2}{*}{$\begin{array}{l}\text { Over- } \\
\text { benef it } \\
\text { Mean }\end{array}$} & \multirow[b]{2}{*}{ S.D. } & \multicolumn{2}{|c|}{$\begin{array}{l}\text { Trend } \\
\text { F-ratios } \\
\end{array}$} \\
\hline & & & & & Linear & $\begin{array}{l}\text { Curvi- } \\
\text { linear }\end{array}$ \\
\hline Wives & $(n=54)$ & $(n=98)$ & $(n=84)$ & & & \\
\hline Content & 3.59 & 3.83 & 3.70 & .43 & $3.71 *$ & $3.89 *$ \\
\hline Happy & 3.59 & 3.82 & 3.73 & .44 & 3.25 & 3.03 \\
\hline Angry & 1.76 & 1.42 & 1.63 & .68 & 1.08 & $7.08 * *$ \\
\hline Guilty & 1.56 & 1.47 & 1.76 & .82 & 1.09 & 3.46 \\
\hline Affect Sum & 3.87 & 4.76 & 4.04 & 1.57 & 1.04 & $9.38 * *$ \\
\hline Husbands & $(n=34)$ & $(n=76)$ & $(n=126)$ & & & \\
\hline Content & 3.59 & 3.79 & 3.73 & .51 & 2.15 & .99 \\
\hline Happy & 3.44 & 3.84 & 3.75 & .51 & $11.36 * *$ & $5.79 * *$ \\
\hline Angry & 1.77 & 1.51 & 1.56 & .64 & 1.22 & .76 \\
\hline Guilty & 1.62 & 1.59 & 1.59 & .68 & .04 & .03 \\
\hline Affect Sum & 3.65 & 4.53 & 4.33 & 1.55 & 3.13 & 2.07 \\
\hline
\end{tabular}

Strong confirmation was found for these expectations for both men and women. Equitably treated women were happier and more satisfied with their marriages than were the overbenefited and the underbenefited women. The quadratic $F$ 's were $7.31, p<.007$ for the "happy with marriage" responses and 4.78, $p<.029$ for the "satisfied with marriage" responses. Equitably treated men were also significantly more happy with their marriages than overbenefited or underbenefited men $\left(F_{4.227}\right.$ [quadratic] $=14.08$, $p<.001)$, and they were more satisfied with their marriages $\left(F_{4.227}\right.$ [quadratic] $=6.37$, $p<.02$; see Table 2). Figure 3 plots mean responses to the happiness and satisfaction questions for underbenefited, equity, and overbenefited women and men.

Together, the results of the content/distress measure and the satisfaction measures provide some validity evidence for the TUW Scales as a measure of equity/inequity in marital relations.

\section{Summary and Conclusions}

Contrary to expectations, it was found that both Daters and Marrieds take similar things into account when assessing the "fairness" of their intimate relations. Ultimately, the major concerns of both groups fell into four areas: (1) Personal Concerns, (2) Emotional Concerns, (3) Day-to-Day Concerns, and (4) Opportunities Gained or Lost. Items reflecting these concerns constitute the TUW Scales.

The reliability and validity of the scales were assessed in two studies. In the reliability study, the total scales proved to be reasonably internally consistent. In the validity assessment study, some evidence for the construct validity of the scales was demonstrated. Despite very restricted variance, the TUW scales were shown to be good predictors of (1) overall affect, measured by Austin's (1974) Mood Scale and of (2) marital satisfaction and happiness. Of course, this is only a 


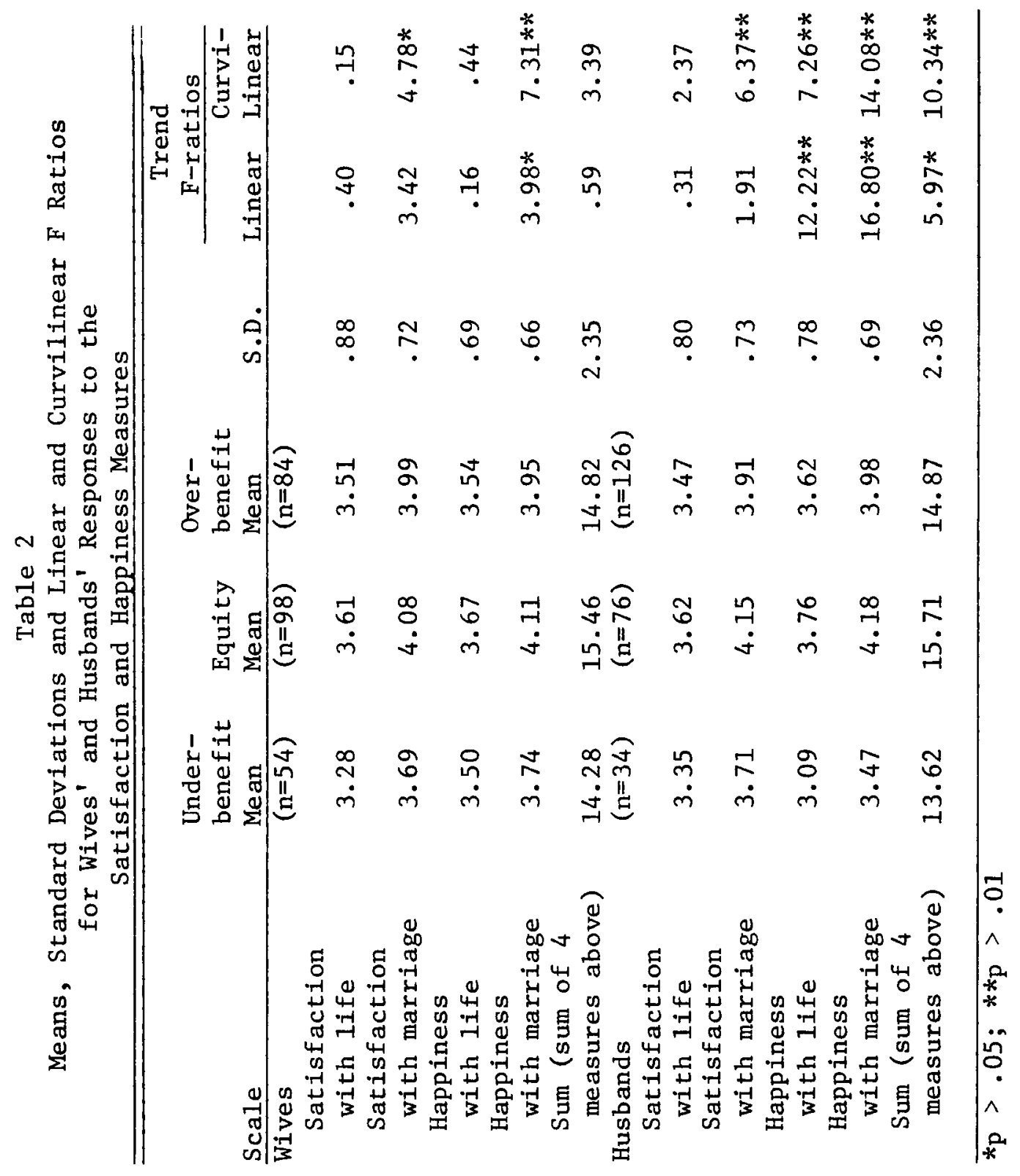


Figure 3

Satisfaction and Happiness with Marriage as a Function of Perceived Equity/Inequity in Marriage
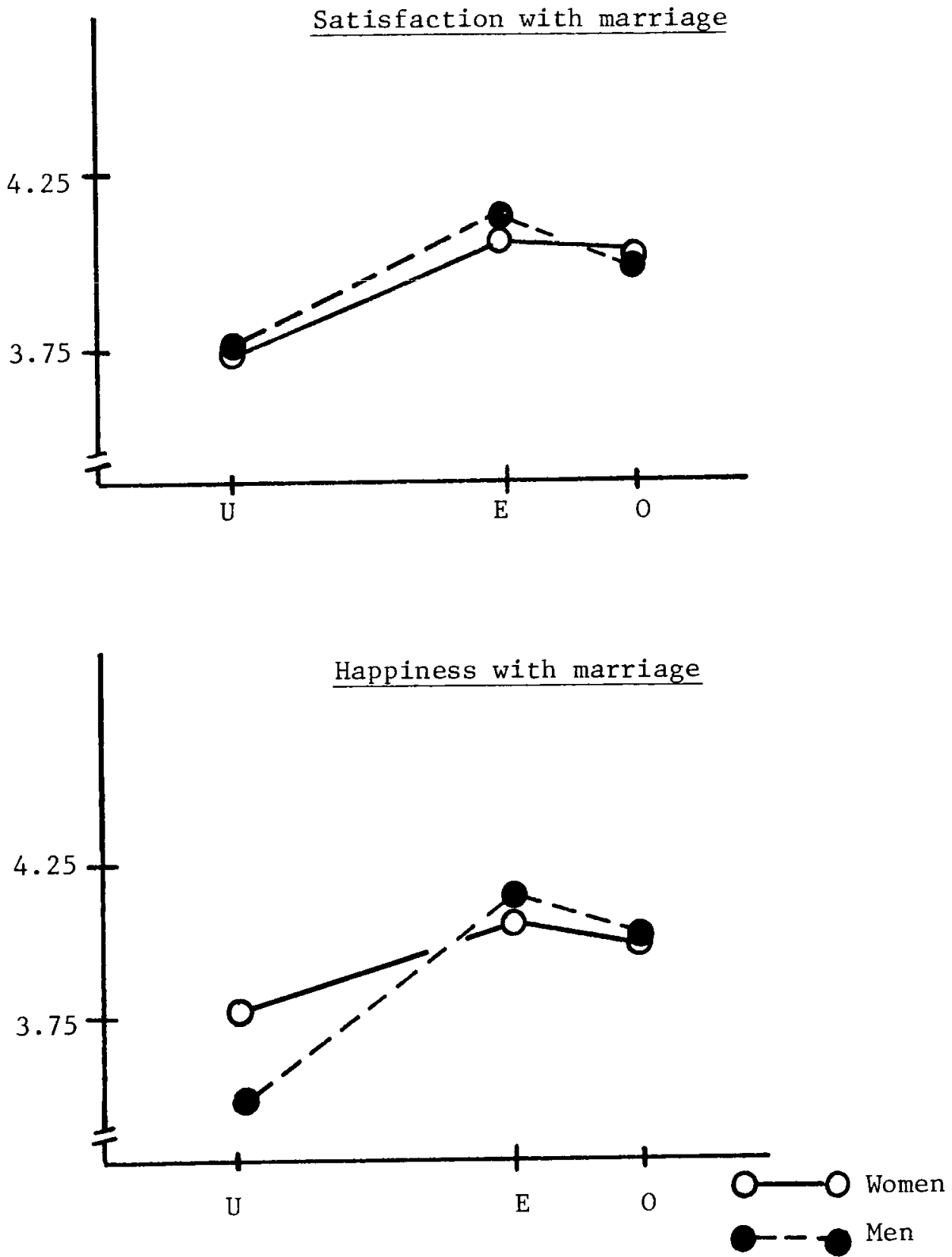
first step in the assessing the validity of the scales.

If any theory is to be accepted by the scientific community, its advocates must provide operational definition of its major concepts. Without operationalization, empirical tests will always be inconclusive. For example, a number of researchers are currently using disparate definitions of equity/inequity in intimate relations (Mills, 1976; Murstein, Cerreto, \& MacDonald, 1977). Not surprisingly, their conclusions about the usefulness of equity theory in predicting how intimates will interact are quite disparate. It is hoped that the development of a measure of equity in intimacy will stimulate further efforts to test the theory.

\section{References}

Adams, J. S. Toward an understanding of inequity. Journal of Abnormal and Social Psychology, 1963, 67, 422-436.

Adams, J. S., \& Freedman, S. Equity theory revisited: Comments and annotated bibliography. In L. Berkowitz (Ed.), Advances in experimental social psychology. New York: Academic Press, 1976.

Austin, W. G. Studies in equity with the world: A new application of equity theory. Unpublished doctoral dissertation, University of Wisconsin, 1974.

Austin, W. G., \& Walster, E. Equity with the world: An investigation of the trans-relational effects of equity and inequity. Sociometry, 1975, 38, 474-496.

Briar, S. Welfare from below: Recipients' views of the public welfare system. California Law Review. 1966, 54, 370-385.

Burgess, E. W., \& Cottrell, L. S. Predicting success or failure in marriage. New York: Prentice-Hall, 1939.

Burgess, E. W., \& Wallin, P. Engagement and marriage. Philadelphia: J. B. Lippincott, 1953.

Dillon, W. S. Gifts and nations. The Hague: Mouton, 1968.

Gross, A., Piliavin, I., Wallston, B., \& Broll, L. When humanitarianism is not humane: Helping-the recipient's view. Paper presented at American Psychological Association, Honolulu, September 1972. (Revised, 1973.)
Hopps, H., Wills, T. A., Weiss, K. L., \& Patterson, G. R. (MICS) Marital interaction coding system. Unpublished manuscript, University of Oregon and Oregon Research Institute, 1972. (See NAPS Document No. 02077 for supplementary material.)

Kelley, H. Personal relationships: Their structures and processes. Hillsdale NJ: Erlbaum, 1979.

Leventhal, G. S. The distribution of rewards and resources in groups and organizations. In L. Berkowitz \& E. Walster (Eds.), Advances in experimental social psychology (Vol. 9). New York: Academic Press, 1976.

Levinger, G. A three-level approach to attraction: Toward an understanding of pair-relatedness. In T. Huston (Ed.), Foundations of interpersonal attraction. New York: Academic Press, 1974.

Mills, J. R. Social relationships and interpersonal attraction. Grant submitted to the National Institute of Mental Health, 1976.

Murstein, B. L. Stimulus-value-role: A theory of marital choice. Journal of Marriage and the Family, 1970, 32, 465-481.

Murstein, B. L., Cerreto, M., \& MacDonald, M. G. A theory and investigation of the effect of exchange orientation on marriage and friendship. Journal of Marriage and the Family, 1977, 39, 543-548.

Nunnally, J. C. Psychometric theory. New York: McGraw-Hill, 1967.

Piliavin, J., \& Piliavin, I. The effect of blood on reactions to a victim. Journal of Personality and Social Psychology, 1972, 23, 353-361.

Pritchard, R., Dunnette, M., \& Jorgenson, E. Effects of perceptions of equity and inequity on worker performance and satisfaction. Journal of Applied Psychology Monograph, 1972, 56, 75-94.

Sager, C. J. Marriage contracts and couple therapy. New York: Brunner/Mazel, 1976.

Stuart, R. B. Operant-interpersonal treatment of marital discord. In C. J. Sager \& H. S. Kaplan (Eds.), Progress in group and family therapy. New York: Brunner/Mazel, 1972.

Traupmann, J. Equity and intimate relations: An interview study of marriage, Unpublished doctoral dissertation, University of Wisconsin, 1978.

Utne, M. K. Equity and intimate relations: $A$ test of the theory in marital interaction. Unpublished doctoral dissertation, University of Wisconsin, 1978.

Walster, G. W. The Walster et al. (1973) equity formula: A correction. Representative Research in Social Psychology, 1975, 6, 65-67.

Walster, E., Walster, G. W., \& Berscheid, E. Equity: Theory and research. Boston: Allyn \& Bacon, 1978. 


\section{Acknowledgments}

Preparation of this manuscript was supported by the McBeath Institute on Aging and Adult Life, University of Wisconsin. Madison WI 53706.

\section{Author's Address}

Send requests for reprints or further information to Jane Traupmann, Center for Research on Women, Wellesley College, Wellesley MA 02181. 